\title{
Intermediate weight changes and follow-up of dietetic treatment in primary health care: an observational study
}

\author{
Lisa D. M. Verberne ${ }^{1 *}\left(\mathbb{D}\right.$, Chantal J. Leemrijse $^{1}$, Markus M. J. Nielen ${ }^{1}$ and Roland D. Friele $e^{1,2}$
}

\begin{abstract}
Background: Primary health care data have shown that most patients who were treated for overweight or obesity by a dietitian did not accomplish the recommended treatment period. It is hypothesised that a slow rate of weight loss might discourage patients from continuing dietetic treatment. This study evaluated intermediate weight changes during regular dietetic treatment in Dutch primary health care, and examined whether weight losses at previous consultations were associated with attendance at follow-up consultations.

Methods: This observational study was based on real life practice data of overweight and obese patients during the period 2013-2017, derived from Dutch dietetic practices that participated in the Nivel Primary Care Database. Multilevel regression analyses were conducted to estimate the mean changes in body mass index (BMI) during six consecutive consultations and to calculate odds ratios for the association of weight change at previous consultations with attendance at follow-up consultations.
\end{abstract}

Results: The total study population consisted of 25,588 overweight or obese patients, with a mean initial BMl of 32.7 $\mathrm{kg} / \mathrm{m}^{2}$. The BMl decreased between consecutive consultations, with the highest weight losses between the first and second consultation. After six consultations, a mean weight loss of $-1.5 \mathrm{~kg} / \mathrm{m}^{2}$ was estimated. Patients who lost weight between the two previous consultations were more likely to attend the next consultation than patients who did not lose weight or gained weight.

Conclusions: Body mass index decreased during consecutive consultations, and intermediate weight losses were associated with a higher attendance at follow-up consultations during dietetic treatment in overweight patients. Dietitians should therefore focus on discussing intermediate weight loss expectations with their patients.

Keywords: Overweight, Obesity, Weight loss, Nutritionists, Primary health care

\section{Background}

In Europe, almost all primary health care systems provide services for the prevention and treatment of overweight and obesity (i.e. having a body mass index $(\mathrm{BMI}) \geq 25 \mathrm{~kg} /$ $\mathrm{m}^{2}$ ) [1]. In the Netherlands, general practitioners (GPs), practice nurses, and dietitians are the main healthcare

\footnotetext{
* Correspondence: lisaverberne@hotmail.com

${ }^{1}$ Nivel, Netherlands Institute for Health Services Research, P.O. Box 1568, Utrecht 3500 BN, The Netherlands

Full list of author information is available at the end of the article
}

professionals to provide these services. Weight management tasks by GPs and practice nurses may consist of regular weight measurements and advisement on nutrition and physical activity [2, 3]. For more intensive guidance on nutritional health care, patients are advised to consult a dietitian. Dietitians are important health care professionals for providing nutritional health care to overweight and obese patients, with the primary aim to achieve and maintain weight loss $[4,5]$. Intensive weight management

(C) The Author(s). 2020 Open Access This article is licensed under a Creative Commons Attribution 4.0 International License, which permits use, sharing, adaptation, distribution and reproduction in any medium or format, as long as you give appropriate credit to the original author(s) and the source, provide a link to the Creative Commons licence, and indicate if changes were made. The images or other third party material in this article are included in the article's Creative Commons licence, unless indicated otherwise in a credit line to the material. If material is not included in the article's Creative Commons licence and your intended use is not permitted by statutory regulation or exceeds the permitted use, you will need to obtain permission directly from the copyright holder. To view a copy of this licence, visit http://creativecommons.org/licenses/by/4.0/ The Creative Commons Public Domain Dedication waiver (http://creativecommons.org/publicdomain/zero/1.0/) applies to the data made available in this article, unless otherwise stated in a credit line to the data. 
improves clinical outcomes, and has the potential to reduce complications of diabetes mellitus type 2 [6].

Data from Dutch primary health care show that most patients who visit a dietitian are referred by their GP and approximately half of these patients are diagnosed with overweight or obesity [7]. Further studies on these data demonstrated that overweight patients who were treated by a dietitian lost approximately one BMI point, corresponding to a weight loss of $3.5 \%$ of initial body weight $[8,9]$. However, most patients did not reach the weight loss goal of $\geq 5 \%$ of initial body weight, and did not accomplish the recommended treatment duration of at least 1 year, as recommended in the guidelines for dietitians.

The effectiveness of weight loss treatment is affected by the combined effects of several factors, including treatment adherence, which is defined as the extent to which a person's behaviour corresponds with the agreed recommendations from the health care provider [10], sociodemographic factors, and physiological responses during weight loss. Previous studies in primary health care settings found patients' health status, sex, age, and socio economic status to be important determinants in health care utilisation [11-13]. Similar determinants were indicated in a meta-analysis of adherence to weight loss interventions, which showed that a poor health, a lower age, and a lower socio economic status were associated with a lower adherence [14]. Several other studies have indicated early weight loss as a predictor for lower drop-out rates in weight loss programs [15-21], suggesting that a slow rate of weight loss might discourage patients from continuing with treatment. The current study evaluated real life practice data to examine the degree of weight loss during follow-up of dietetic treatment and its association with attendance at follow-up consultations.

\section{Methods}

\section{Study design}

This observational study was based on routinely recorded data by Dutch dietetic practices that participated in the Nivel Primary Care Database (Nivel-PCD) within the period 2013-2017. The Nivel-PCD contains anonymised patient data from electronic health records, extracted from software programmes used by primary care dietetic practices, as previously described by Verberne et al. [9].

\section{Study population}

All electronic health records were selected from the Nivel-PCD for patients $\geq 18$ years who had a recorded diagnosis of being overweight or obese (BMI $\geq 25 \mathrm{k} / \mathrm{m}^{2}$ ), and who started a treatment with the dietitian between January 2013 and December 2016. Patients were excluded if they had an additional recorded diagnosis for which weight loss might not be the goal for treatment, e.g. for gestational diabetes.

\section{Measures}

Information on sex, age, BMI, dietetic diagnoses, four digit-postal codes of the patient's neighbourhood, and consultation dates, were derived from the electronic health records of the patients. A variable with three categories was established that defined whether a patient had other recorded dietetic diagnoses 1) no other recorded diagnosis; 2) a recorded diagnosis of diabetes mellitus type 2, hypertension, and/or hypercholesterolemia; and 3) a recorded diagnosis other than diabetes mellitus type 2, hypertension, or hypercholesterolemia. The neighbourhood social status score in 2014 was obtained from the Netherlands Institute for Social Research (SCP) [22]. This is a composite measure on the four digit-postal code level, established with four indicators, i.e. mean income, the proportion of people with a low education level or a low income, and unemployment. For the present study, the social status score was categorised according to the quartiles of the status score in the Netherlands.

\section{Statistical analyses}

Statistical analyses were performed using STATA 14.2. Descriptive statistics were used to present patient characteristics. All recorded one to one consultations were counted that took place within 1 year after start of the treatment to calculate the attrition rate. A multilevel linear regression analysis was performed to estimate the mean changes in BMI during six consecutive consultations, using data from all patients who had a recorded $\mathrm{BMI}$ at the first consultation (the initial BMI) and an available BMI measure at one or more of the five following consultations. The initial BMI was used as reference to calculate the change in BMI at each time point. Random intercepts were included to account for clustered data of patients within dietetic practices and for repeated measurements within patients.

Weight changes between two consecutive consultations were calculated by subtracting the BMI recorded at the first consultation from the BMI recorded at the last consultation for all patients with available BMI measurements. Subsequently, three categories of weight change were established. The category "no weight loss" (change in BMI: $\geq 0 \mathrm{~kg} / \mathrm{m}^{2}$ ) was used as a reference. Furthermore, two categories of weight loss were created: "moderate weight loss", and "high weight loss". The cut off value for these two categories was based on the median weight loss between consultations, which was approximately $-0.5 \mathrm{~kg} / \mathrm{m}^{2}$. We used a multilevel logistic regression, including a random intercept to account for 
clustered data of patients (level 1) within dietetic practices (level 2), to calculate the odds ratios for attendance at consultation 3, 4, 5, and 6 , across the categories of weight change between consultation 1 \& 2, consultation $2 \& 3$, consultation $3 \& 4$, and consultation 4 \& 5, respectively. A second model was used to control for potential confounding factors, and included variables for sex, age, initial BMI, dietetic diagnosis, and social status score. A two-tailed $P$-value of $<0.05$ was considered statistically significant.

\section{Results}

The total study population consisted of 25,588 patients from 77 dietetic practices. Table 1 shows the characteristics of the study population. Patients were on average 54 years old, had a mean BMI of $32.7 \mathrm{~kg} / \mathrm{m}^{2}$ at the start of treatment, and $64 \%$ were female. Sixteen percent of the 25,588 patients dropped out after one consultation and approximately a quarter of the patients attended six consultations or more, corresponding to a mean treatment duration of 6.5 months (Fig. 1). The time between consultations increased from 28 days between the first and second consultation to 42 days after the third consultation. For $79 \%$ of the study patients, a BMI was recorded at the first consultation (i.e. the initial BMI). At each following consultation, BMI was recorded for approximately $70 \%$ of the patients. The BMI decreased during consecutive consultations, with the highest weight losses occurring between the first two consultations. After six consultations, a mean weight loss of $-1.5 \mathrm{~kg} / \mathrm{m}^{2}$ was estimated (Fig. 2). This is equivalent to a weight reduction of $4 \%$ of initial weight (average initial weight $95.9 \mathrm{~kg}$ ). A similar weight loss pattern was shown in additional

Table 1 Patient characteristics ( $N=25,588)$

\begin{tabular}{ll}
\hline & $\begin{array}{l}\text { Percent/Mean } \\
\text { (SD) }\end{array}$ \\
\hline Sex (female) & 63.9 \\
Age (years) & $53.7(15.2)$ \\
Initial body mass index $\left(\mathrm{kg} / \mathrm{m}^{2}\right)$ & $32.7(5.4)$ \\
Initial body weight $(\mathrm{kg})$ & $95.9(18.5)$ \\
Dietetic diagnosis & \\
No other diagnosis & 38.9 \\
Diagnosis of diabetes mellitus type 2, & 48.3 \\
hypertension, and/or hypercholesterolemia & \\
A diagnosis other than diabetes mellitus type 2, & 12.9 \\
hypertension, or hypercholesterolemia & \\
Neighbourhood social status score: & \\
Quartile 1-low & 36.7 \\
Quartile 2 & 23.9 \\
Quartile 3 & 18.1 \\
Quartile 4-high & 21.3 \\
\hline
\end{tabular}

analyses that included only patients who attended six or more consultations with a recorded BMI at each consultation. Table 2 shows the association of attendance at a consultation with the weight change between the two previous consultations. Patients who lost weight between the two previous consultations were more likely to attend the next consultation than patients who did not lose weight or gained weight. These associations were present in both the crude and adjusted models.

\section{Discussion \\ Main findings}

This study evaluated intermediate weight changes during regular dietetic treatment and its association with attendance at follow-up consultations in Dutch primary health care. The study elaborates on our previous study which showed that a higher weight loss was associated with a longer treatment time [9]. The present study showed that $16 \%$ of the patients only had one consultation, which is corresponding to findings of an Italian study that reported a dropout rate of $21 \%$ after 1 month in an obesity treatment programme in a clinical setting [16]. Furthermore, we showed that the mean change in BMI between consultations decreased from approximately $-0.5 \mathrm{~kg} / \mathrm{m}^{2}$ at the second consultation to approximately $-0.25 \mathrm{~kg} / \mathrm{m}^{2}$ at the following consultations, which is in accordance with reviews on clinical trials that also observed a diminishing trend for weight loss over time [23-25]. We found intermediate weight losses during dietetic treatment in primary health care to be associated with a higher attendance rate at the next consultation. Similar findings have also been shown in other studies in real life settings, other than primary health care $[16,18]$, and in studies on dietary weight loss interventions, demonstrating an association of early weight loss with the dropout rate $[15,17,19-21]$. For example, Batterham et al. found that people with a weight loss $\leq 2 \%$ were five times more likely to dropout from a weight loss trial than those with a weight loss > $2 \%$ in the first month [15].

\section{Strengths and limitations}

We used a large database with real life practice data from overweight and obese patients treated by dietitians in Dutch primary health care. This database includes all information relevant for reimbursement and treatment purposes. In addition, we could link data on social status score to the patient records. We were therefore able to control for important variables related to health care utilisation.

A limitation of the study was the availability of anthropometric data. Measurements of BMI were not recorded at all consultations or for all patients. Additional analyses showed that patients who attended the next 


\section{Patients' attendance at consultations Days between consultations Median (Q1-Q3)}

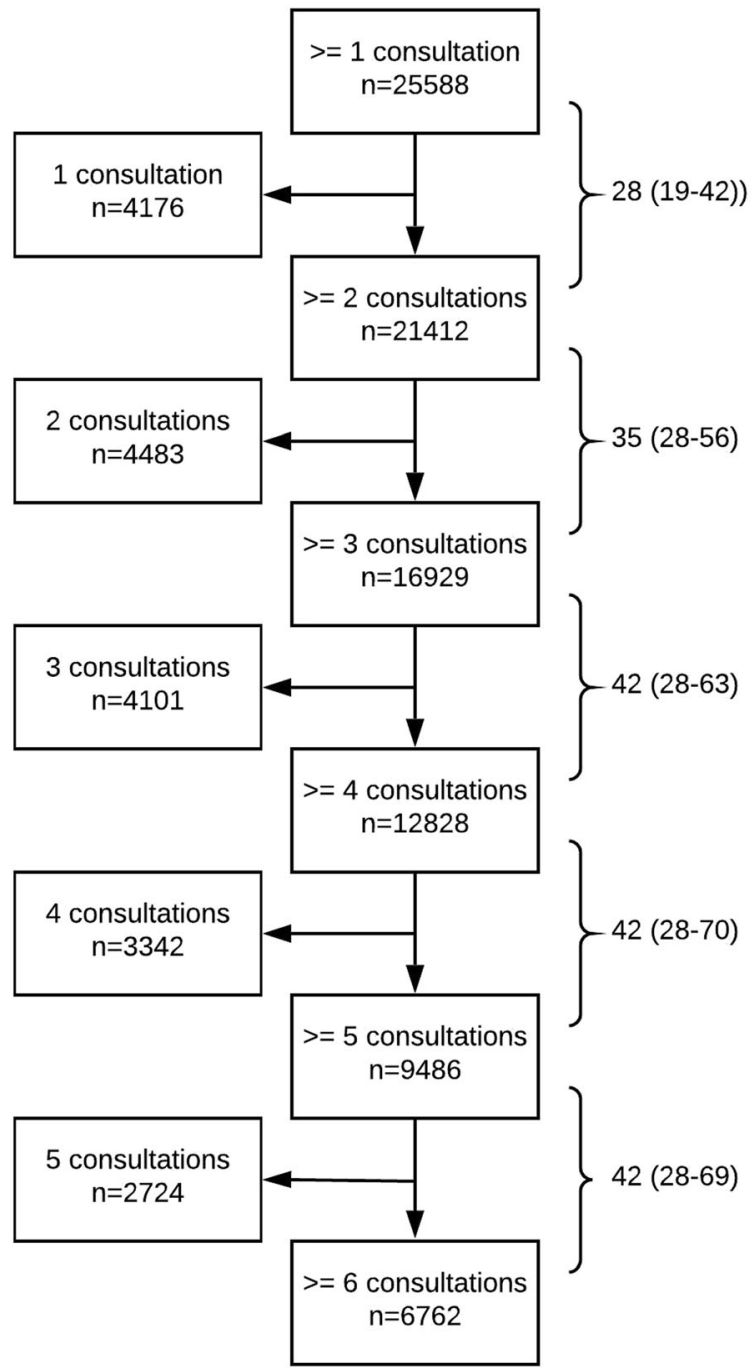

Fig. 1 Attrition rate during dietetic treatment

consultation were more likely to have had their BMI recorded during the previous consultation (approximately $70 \%)$ than patients who did not attend the next consultation (approximately 60\%) (data not shown). We could, however, not check whether missing data on BMI were affected by disappointing weight loss results, or by software issues, or recording habits of the dietitian. For further research it would be interesting to enhance the dataset with information on diagnostic measurements and drug prescriptions from electronic health data of general practices.

Another issue that needs consideration is that we only evaluated attendance at follow-up consultations, which does not necessarily mean that a patient is following the instructions for lifestyle changes as recommended by their dietitian. Information about the patients' compliance with the recommended lifestyle changes by their dietitian was not available in our database. Furthermore, we were not able to evaluate the dietitian-patient relationship, which has been shown to have an important role in adherence to nutritional treatment [26].

\section{Implications of the findings}

We showed that the BMI of overweight and obese patients who were treated by dietitians decreased between consecutive consultations, with the highest weight loss between the first and second consultation. This early weight loss is important, since it has been associated 


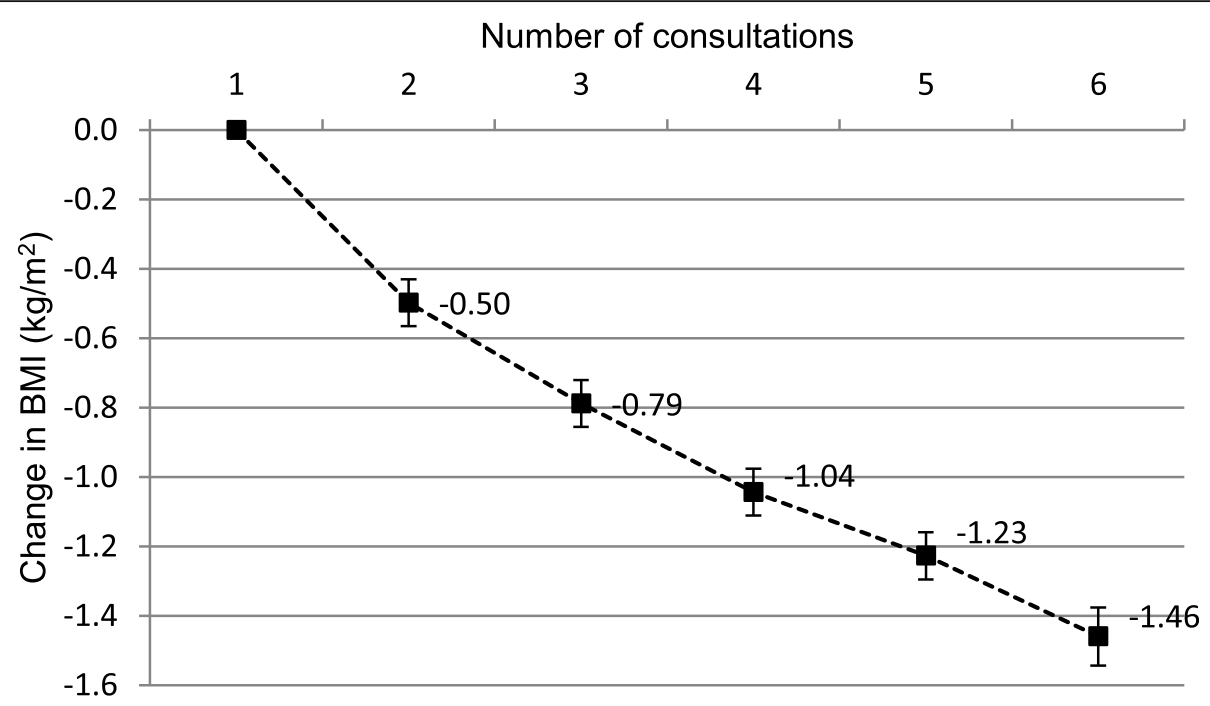

Fig. 2 Mean change in body mass index (BMI) between six consecutive consultations. Means are adjusted for clustered data of patients within dietetic practices, and for repeated measurements within patients. The error bars represent the $95 \%$ confidence intervals around the means

with successful weight loss and weight maintenance in the long-term [17, 27-29]. However, after these first consultations, dietitians should focus on discussing realistic weight loss expectations with their patients. Refining intermediate weight loss goals would possibly help to improve the continuation of treatment. Furthermore, a higher frequency of consultations with a dietitian might aid an earlier intervention in patients who are not complying with the advice from their dietitian [24, 30].
As supported by Stubbs et al. [31], future research is recommended to examine treatments that are sensitive to patients' individual needs. Possibly an algorithm can help to identify and assess patients for their optimal therapy [32].

Participation in a weight loss program requires a longterm investment from patients. In the present research we showed that BMI decreased during consecutive consultations with a dietitian. The majority of the patients,

Table 2 The association of attendance at a consultation with weight change between the two previous consultations

\begin{tabular}{|c|c|c|c|}
\hline & \multicolumn{3}{|c|}{ Category of weight change between two previous consultations } \\
\hline & no weight loss & moderate weight loss & high weight loss \\
\hline Attendance at 3rd consultation (yes/no) ${ }^{a}$ & $2548 / 705$ & $3322 / 706$ & $4810 / 864$ \\
\hline Model 1 & ref. & $1.28(1.14-1.44)$ & $1.48(1.33-1.67)$ \\
\hline Model 2 & ref. & $1.28(1.14-1.44)$ & $1.40(1.25-1.57)$ \\
\hline Attendance at 4 th consultation $(\text { yes } / \mathrm{no})^{\mathrm{b}}$ & $2363 / 762$ & $2914 / 662$ & $2803 / 639$ \\
\hline Model 1 & ref. & $1.40(1.24-1.58)$ & $1.40(1.24-1.58)$ \\
\hline Model 2 & ref. & $1.44(1.27-1.64)$ & $1.35(1.19-1.54)$ \\
\hline Attendance at 5 th consultation (yes/no $)^{c}$ & $2131 / 786$ & $2100 / 527$ & $1844 / 497$ \\
\hline Model 1 & ref. & $1.43(1.26-1.62)$ & $1.33(1.17-1.52)$ \\
\hline Model 2 & ref. & $1.40(1.21-1.60)$ & $1.27(1.11-1.47)$ \\
\hline Attendance at 6 th consultation (yes/no) ${ }^{d}$ & $1739 / 735$ & $1511 / 422$ & $1035 / 357$ \\
\hline Model 1 & ref. & $1.44(1.25-1.66)$ & $1.21(1.04-1.41)$ \\
\hline Model 2 & ref. & $1.46(1.25-1.70)$ & $1.17(0.99-1.38)$ \\
\hline
\end{tabular}

Odds ratios are presented with their $95 \%$ confidence intervals

Model 1: adjusted for clustered data of patients within dietetic practices

Model 2: model 1+ adjustment for sex, age, initial body mass index (BMI), dietetic diagnosis, and social status score

${ }^{\text {a }}$ Weight loss category according to change in BMI between consultations 1 \& 2

${ }^{b}$ Weight loss category according to change in BMI between consultations $2 \& 3$

c Weight loss category according to change in BMI between consultations 3 \& 4

${ }^{d}$ Weight loss category according to change in BMI between consultations 4 \& 5 
however, did not attend more than six consultations, and did not reach clinically relevant weight loss goals. In contrast to most previous studies that have demonstrated the effectiveness of weight loss programs in interventional trials, with probably highly motivated patients, we studied dietetic treatment in real life practice where financial and environmental factors play an important role. To illustrate, in the Netherlands, generally, only $3 \mathrm{~h}$ of dietetic healthcare are covered by the basic health insurance, and it has been shown that limiting the reimbursement of dietetic treatment resulted in fewer patients visiting the dietitian, since many patients cannot or are unwilling to pay for dietetic treatment [33]. We, therefore, agree with Wadden et al. [34], that more research is needed to find effective methods for weight loss treatment in primary care, also taking into account financial and environmental factors.

\section{Conclusions}

This study was conducted to gain a greater understanding of the adherence to dietetic treatment in primary health care. We demonstrated that the BMI of overweight and obese patients who were treated by dietitians in primary health care decreased between consecutive consultations, and found that intermediate weight losses during dietetic treatment were associated with a higher attendance at follow-up consultations. In order to improve the retention rate of patients during dietetic treatment, dietitians should focus on discussing intermediate weight loss expectations with their patients.

\section{Abbreviations}

BMI: Body mass index; Nivel-PCD: Nivel Primary Care Database

\section{Acknowledgements}

We would like to thank Tessa Jansen for processing the data on social status scores.

\section{Authors' contributions}

All authors were involved in the conception and design of the study. LV carried out the data analyses. CL, MN, and RF critically commented on the results and implications. LV produced the first draft of the manuscript. All authors contributed to and approved the final manuscript.

\section{Funding}

The data of this study were collected within the research infrastructure of the Nivel Primary Care Database, which is funded by the Dutch Ministry of Health Welfare and Sports. The funder had no role in the analyses, interpretation of data and the writing of the manuscript.

\section{Availability of data and materials}

The datasets used in the current study are available from the corresponding author on reasonable request.

\section{Ethics approval and consent to participate}

Steering committees with representatives from national associations of health care providers decide about the access and use of the data from the Nivel Primary Care Database. For the current study permission was obtained from the Dutch Association of Dietitians (NVD). This study has been approved by the applicable governance bodies of the Nivel Primary Care Database under no. NZR-00317.043. Dutch law allows the use of electronic health records for research purposes under certain conditions. According to this legislation, neither obtaining informed consent from patients nor approval by a medical ethics committee is obligatory for this type of observational study containing no directly identifiable data from the Nivel Primary Care Database (Dutch Civil Law, Article 7:458).

\section{Consent for publication}

Not applicable.

\section{Competing interests}

The authors declare that they have no competing interests.

\section{Author details}

${ }^{1}$ Nivel, Netherlands Institute for Health Services Research, P.O. Box 1568, Utrecht 3500 BN, The Netherlands. ${ }^{2}$ Tilburg School of Social and Behavioral Sciences, Tilburg University, Tranzo, P.O. Box 90153, Tilburg 5000 LE, The Netherlands.

Received: 27 May 2019 Accepted: 1 September 2020

Published online: 16 November 2020

\section{References}

1. World Health Organization. Prevention and control of noncommunicable diseases in the European Region: a progress report. 2014. http://www.euro. who.int/_data/assets/pdf_file/0004/235975/Prevention-and-control-ofnoncommunicable-diseases-in-the-European-Region-A-progress-report-Eng. pdf?ua=1. Accessed 15 May 2019.

2. Van Binsbergen J, Langens F, Dapper A, Van Halteren M, Glijsteen R, Cleyndert G, et al. NHG-Standaard Obesitas. Huisarts Wet. 2010;53(11):609-25.

3. Kloek CJ, Tol J, Veenhof C, van der Wulp I, Swinkels IC. Dutch general practitioners' weight management policy for overweight and obese patients. BMC Obes. 2014:1:2

4. Millen BE, Wolongevicz DM, Nonas CA, Lichtenstein AH. 2013 American Heart Association/American College of Cardiology/the Obesity Society guideline for the management of overweight and obesity in adults: implications and new opportunities for registered dietitian nutritionists. J Acad Nutr Diet. 2014;114(11):1730-5.

5. The Dutch Association of Dietetics. Artsenwijzer Dietetiek. 2017. http:// artsenwijzerdietetiek.nl/te-hoog-gewicht/te-hoog-gewicht-bij-volwassenen. Accessed 15 May 2019.

6. Lean ME, Leslie WS, Barnes AC, Brosnahan N, Thom G, McCombie L, et al. Durability of a primary care-led weight-management intervention for remission of type 2 diabetes: 2-year results of the DiRECT open-label, cluster-randomised trial. Lancet Diabetes Endocrinol. 2019;7(5):344-55.

7. Flinterman L, Leemrijse C, Schermer T. Zorg door de diëtist: jaarcijfers 2017 en trendcijfers 2013-2017. Nivel. 2018. https://nivel.nl/nl/publicatie/zorg-door-dedietist-jaarcijfers-2017-en-trendcijfers-2013-2017. Accessed 15 May 2019.

8. Tol J, Swinkels IC, de Bakker DH, Seidell J, Veenhof C. Dietetic treatment lowers body mass index in overweight patients: an observational study in primary health care. J Hum Nutr Diet. 2014;27(5):426-33.

9. Verberne LD, Leemrijse C, Nielen MM, Friele RD. Achievement of weight loss in patients with overweight during dietetic treatment: an observational study in primary healthcare. PLoS One. 2019;14(11):e0225065.

10. World Health Organization. Adherence to long-term therapies: evidence for action. 2003. https://www.who.int/chp/knowledge/publications/adherence full report.pdf. Accessed 15 May 2019.

11. Mukhtar TK, Bankhead C, Stevens S, Perera R, Holt TA, Salisbury C, et al. Factors associated with consultation rates in general practice in England, 2013-2014: a cross-sectional study. Br J Gen Pract. 2018;68(670):e370-7.

12. Swinkels IC, Wimmers RH, Groenewegen PP, van den Bosch WJ, Dekker J, van den Ende $\mathrm{CH}$. What factors explain the number of physical therapy treatment sessions in patients referred with low back pain; a multilevel analysis. BMC Health Serv Res. 2005;5:74.

13. Tol J, Swinkels IC, Spreeuwenberg PM, Leemrijse CJ, de Bakker DH, Veenhof C. Factors associated with the number of consultations per dietetic treatment: an observational study. BMC Health Serv Res. 2012;12:317.

14. Lemstra M, Bird Y, Nwankwo C, Rogers M, Moraros J. Weight loss intervention adherence and factors promoting adherence: a meta-analysis. Patient Prefer Adherence. 2016:10:1547-59.

15. Batterham M, Tapsell LC, Charlton KE. Predicting dropout in dietary weight loss trials using demographic and early weight change characteristics: implications for trial design. Obes Res Clin Pract. 2016;10(2):189-96. 
16. Colombo O, Ferretti W, Ferraris C, Trentani C, Vinai P, Villani S, et al. Is dropout from obesity treatment a predictable and preventable event? Nutr J. 2014;13:13.

17. Handjieva-Darlenska T, Holst C, Grau K, Blaak E, Martinez JA, Oppert JM, et al. Clinical correlates of weight loss and attrition during a 10-week dietary intervention study: results from the NUGENOB project. Obes Facts. 2012;5(6): 928-36.

18. Hemmingsson E, Johansson K, Eriksson J, Sundstrom J, Neovius M, Marcus C. Weight loss and dropout during a commercial weight-loss program including a very-low-calorie diet, a low-calorie diet, or restricted normal food: observational cohort study. Am J Clin Nutr. 2012;96(5):953-61.

19. Messier V, Hayek J, Karelis AD, Messier L, Doucet E, Prud'homme D, et al. Anthropometric, metabolic, psychosocial and dietary factors associated with dropout in overweight and obese postmenopausal women engaged in a 6month weight loss programme: a MONET study. Br J Nutr. 2010;103(8):1230-5.

20. Packianathan I, Sheikh M, Boniface D, Finer N. Predictors of programme adherence and weight loss in women in an obesity programme using meal replacements. Diabetes Obes Metab. 2005;7(4):439-47.

21. Yackobovitch-Gavan M, Steinberg DM, Endevelt R, Benyamini Y. Factors associated with dropout in a group weight-loss programme: a longitudinal investigation. J Hum Nutr Diet. 2015;28(Suppl 2):33-40.

22. The Netherlands Institute for Social Research. Neighbourhood status in the Netherlands. 2014. https:/www.scp.nl/Onderzoek/Lopend_onderzoek/A_Z_ alle_lopende_onderzoeken/Statusscores. Accessed 5 Apr 2019.

23. Dansinger ML, Tatsioni A, Wong JB, Chung M, Balk EM. Meta-analysis: the effect of dietary counseling for weight loss. Ann Intern Med. 2007;147(1):41-50

24. Finkler E, Heymsfield SB, St-Onge MP. Rate of weight loss can be predicted by patient characteristics and intervention strategies. J Acad Nutr. 2012; 112(1):75-80.

25. Wadden TA, Butryn ML, Hong PS, Tsai AG. Behavioral treatment of obesity in patients encountered in primary care settings: a systematic review. JAMA. 2014;312(17):1779-91.

26. Endevelt R, Gesser-Edelsburg A. A qualitative study of adherence to nutritional treatment: perspectives of patients and dietitians. Patient Prefer Adherence. 2014;8:147-54.

27. Elfhag K, Rössner S. Initial weight loss is the best predictor for success in obesity treatment and sociodemographic liabilities increase risk for dropout. Patient Educ Couns. 2010;79(3):361-6.

28. Hadžiabdić MO, Mucalo I, Hrabač P, Matić T, Rahelić D, Božikov V. Factors predictive of drop-out and weight loss success in weight management of obese patients. J Hum Nutr Diet. 2015;28(Suppl 2):24-32.

29. Postrach E, Aspalter R, Elbelt U, Koller M, Longin R, Schulzke JD, et al. Determinants of successful weight loss after using a commercial web-based weight reduction program for six months: cohort study. J Med Internet Res. 2013;15(10):e219.

30. Raatz SK, Wimmer JK, Kwong CA, Sibley SD. Intensive diet instruction by registered dietitians improves weight-loss success. J Am Diet Assoc. 2008; 108(1):110-3.

31. Stubbs J, Whybrow S, Teixeira P, Blundell J, Lawton C, Westenhoefer J, et al. Problems in identifying predictors and correlates of weight loss and maintenance: implications for weight control therapies based on behaviour change. Obes Rev. 2011;12(9):688-708.

32. Romanelli RJ, Sudat S, Huang Q, Pressman AR, Azar K. Early weight loss and treatment response: data from a lifestyle change program in clinical practice. Am J Prev Med. 2020;58(3):427-35.

33. Tol, J. Dietetics and weight management in primary health care. Nivel. 2015. https://www.nivel.nl/nl/publicatie/dietetics-and-weight-managementprimary-health-care-dietetiek-en-gewichtsmanagement-de. Accessed 12 Aug 2020

34. Wadden TA, Butryn ML, Byrne KJ. Efficacy of lifestyle modification for longterm weight control. Obes Res. 2004;12(Suppl 12):151s-162s.

\section{Publisher's Note}

Springer Nature remains neutral with regard to jurisdictional claims in published maps and institutional affiliations.

\section{Ready to submit your research? Choose BMC and benefit from:}

- fast, convenient online submission

- thorough peer review by experienced researchers in your field

- rapid publication on acceptance

- support for research data, including large and complex data types

- gold Open Access which fosters wider collaboration and increased citations

- maximum visibility for your research: over $100 \mathrm{M}$ website views per year

At BMC, research is always in progress.

Learn more biomedcentral.com/submissions 